\title{
Helicobacter pylori Infection and Dietary Factors Act Synergistically to Promote Gastric Cancer
}

\author{
Negin Raei ${ }^{1 *}$, Bahador Behrouz ${ }^{2 *}$, Saber Zahri ${ }^{1}$, Saeid Latifi-Navid ${ }^{1}$
}

\begin{abstract}
However, the incidence of gastric cancer (GC) has been decreased in past decades; GC is the second cause of cancer related death in the world. Evidence has illustrated that several factors including Helicobacter pylori $(H$. pylori) infection, host genetics, and environmental factors (smoking and particularly diet) may play a crucial role in gastric carcinogenesis. It has been demonstrated that high consumption of fresh fruits, vegetables, high level of selenium and zinc in drinking water, sufficient iron, and cholesterol protect against GC, while; smoked , pickled, and preserved foods in salt, and nitrites increase the risk of GC. Epidemiological studies have also proved that $H$. pylori infection and a high salt diet could independently induce atrophic gastritis and intestinal metaplasia. Recently, studies have been demonstrated that dietary factors directly influence $H$. pylori virulence. The use of appropriate diet could reduce levels of $\boldsymbol{H}$. pylori colonization or virulence and prevent or delay development of peptic ulcers or gastric carcinoma. This is attractive from a number of perspectives including those of cost, treatment tolerability, and cultural acceptability. This review will describe new insights into the pathogenesis of $\boldsymbol{H}$. pylori in relation to environmental factors, especially dietary, not only to find the developed means for preventing and treating GC, but also for understanding the role of chronic inflammation in the development of other malignancies.
\end{abstract}

Keywords: Helicobacter pylori - dietary factors - gastric cancer

Asian Pac J Cancer Prev, 17 (3), 917-921

\section{Introduction}

The incidence of gastric cancer (GC) has been declined over time, but it is the second cause of death from cancer in the world (Jemal et al., 2011; de Martel et al., 2012; Cover and Peek, 2013; Ferlay et al., 2013; Epplein et al., 2014). H. pylori infects and persists within the stomach of most of the world's population causing chronic inflammation within stomach that can result in gastritis, peptic ulcer disease and cancer. This bacterium is the major cause of acute or chronic gastritis, peptic ulcerations (PU) disease, gastric adenocarcinoma and gastric mucosaassociated lymphoid tissue (MALT) lymphoma. In most of the cases, the infection remains asymptomatic during an individual life, but only a small proportion of infected individuals develops GC (Megraud, 2001; Matsuhisa et al., 2003). As mentioned, various types of cancer can be generated in the stomach, involving adenocarcinoma and lymphoma; however, adenocarcinoma is the most common cancer. Histologically, there are two types of gastric adenocarcinoma (intestinal-type and diffusetype) (Correa, 1992). The gastric adenocarcinoma is often diagnosed late in the course of disease. Therefore, it is crucial to recognize the factors that take part in the occurrence of this malignancy, individuals who are at high risk, and developing means for GC prevention (Cover and Peek, 2013). The gastric adenocarcinoma has remarkably variable incidence worldwide. The high incidence areas are East Asia, Central America, parts of South America, and Eastern Europe (Sonnenberg, 2010; de Martel et al., 2012; Soerjomataram et al., 2012). Over the past century the incidence of tumors in the distal stomach has been decreased, despite the decreasing of gastric adenocarcinomas of the distal stomach over time, a steady increase has been reported about the proximal stomach and gastroesophageal junction in the United States and Europe (Wu et al., 2007; Sonnenberg, 2010; Haile et al., 2012). Diet has long been thought to be correlated with GC risk, most of the published studies have been reported that there is a synergistic interaction between the dietary factors and the $H$. pylori infection in relation to GC risk (Yamaguchi and Kakizoe, 2001).

\section{H. pylori Virulence Factors Promote GC}

Studies have been shown that there is a genetic variation among isolates of $H$. pylori (Blaser and Berg, 2001). H. pylori harbors a $40 \mathrm{~kb}$ chromosomal region,

${ }^{1}$ Department of Biology, Faculty of Sciences, University of Mohaghegh Ardabili, Ardabil, ${ }^{2}$ Department of Microbiology, School of Medicine, Tehran University of Medical Sciences, Tehran,Iran*For correspondence: bahador.behroz3@gmail.com,neginrai@ yahoo.com 
which is known as the cag pathogenicity island (PAI). (Akopyants et al., 1998). The cag PAI is a pathogenicity island in the $H$. pylori genome and encodes numerous genes that, upon cell contact, are expressed and assembled into the needle-like type 4 secretion system (T4SS). $H$. pylori T4SS binds the integrin $\beta 1$ receptor that is located on the basal membrane and transfers the cytotoxin associated gene $\mathrm{A}(\operatorname{cag} A)$ which is also encoded by the cag PAI (Shaffer et al., 2011). Once inside the cell, cagA is tyrosin phosphorylated on specific EPIYA motifs by host kinases, and phosphorylated $\operatorname{cag} A$ activates host cellular phosphatase (SHP-2) that results in humming bird phenotype within host epithelial cells (Higashi et al., 2002).

Non-phosphorylated cagA manipulates PAR1b and promotes loss of cell polarity. Moreover, it interacts with the epithelial tight-junction scaffolding protein ZO-1 and the transmembrane protein junctional adhesion molecule-A (JAM-A) resulting in aberrations in tight junction function at bacterial adherence site (Amieva et al., 2003 ), and also activates $\beta$-catenin which upregulates the genes which are involved in cancer progression (Franco et al., 2005). Due to the mentioned activities $\operatorname{cag} A$ has been known as bacterial oncoprotein (Murata-Kamiya et al., 2007).

Another $H$. pylori virulence factor that is associated with the development of GC is the secreted vacuolating cytotoxin A (VacA) toxin (Cover and Blanke, 2005; Boquet and Ricci, 2012). All strains of $H$. pylori harbor vacA gene but only in $40 \%$ of them VacA might be expressed. The vacA gene displays an allelic diversity in five various regions: the single region s (alleles: $\mathrm{s} 1 \mathrm{a}, \mathrm{s} 1 \mathrm{~b}$, $\mathrm{s} 1 \mathrm{c}$ and $\mathrm{s} 2$ ), the medium region $\mathrm{m}$ (alleles: $\mathrm{m} 1$ and $\mathrm{m} 2$ ), the intermediate region i (alleles: i1 and i2), the deletion region $\mathrm{d}$ (alleles: $\mathrm{d} 1$, no deletion and $\mathrm{d} 2$, with deletion of 69 to $81 \mathrm{bp}$ ) and the c region (alleles: c1, with deletion of 15 bp and c2, no deletion) (Rhead et al., 2007; Ogiwara et al., 2009). The combination of mentioned sequences results in VacA protein, which the polymorphism of VacA is crucial in toxin activity: e.g., the s1 allele, especially in combination with the $\mathrm{m} 1$ allele, is highly associated with the risk of developing PU and GC (Ferreira et al., 2012). These extensive polymorphisms are therefore strongly associated with the risk of PU (gastric ulcer or duodenal ulcer) and gastric precancerous lesions (non-atrophic gastritis or intestinal metaplasia) or GC (Gonzalez et al., 2011; Winter et al., 2014; Honarmand-Jahromy et al., 2015). VacA induces apoptosis in gastric epithelial cells, through stimulating the release of cytochrome $\mathrm{C}$ from mitochondria, which results in the activation of caspase-3 in apoptosis pathway (Cover et al., 2003). VacA can also lead to changes in several immune cells involving, T cells, B cells, neutrophils, mast cells and macrophages (Torres et al., 2007).

$H$. pylori colonizes in the gastric mucus, a small fraction of bacteria can reach to the host cells and adhere via the expression of adhesions. The H.pylori genome involves about 30 hop genes, which code the outer membrane proteins (OMPs); their cellular localization hints that these proteins are involved in adherence or transport of nutrients. One of these genes that has been known to be correlated with GC risk is Blood group Antigen Binding Adhesin, BabA which binds sialyle-lewis b (Suzuki et al., 2012). It has been proved that BabA is expressed more commonly by cag PAI positive strains (Hennig et al., 2004). Furthermore, patients infected with $H$. pylori harboring cag PAI are at high risk of GC (Cover and Peek, 2013).

\section{Environmental Factors and GC Risk}

\section{Smoking}

Tobacco use is associated with an increased risk for GC.A meta-analysis concluded that the cumulative risk of GC risk in male smokers was more than female smokers, in comparison to individuals who never smoke. The analysis showed that relative risk (RR) was increased from 1.3 for the lowest intake to 1.7 for the smoking of about 30 cigarettes per day, it was demonstrated that smoking was remarkably associated with both cardia and noncardia cancer and the RR was 1.87 and 1.60 , respectively (Ladeiras-Lopes et al., 2008; Shikata et al., 2008). Another extensive review by International Agency for Research on Cancer (IARC) has been shown that there was a consistent and causal association of stomach cancer with cigarette smoking in both men and women. There was more than $40 \%$ of the reduction in male cancer deaths between 1991 and 2003 contributed to the decline in smoking in the last half century. It has been proved that smoking had a remarkable correlation with both gastric cardia cancer and non-cardia cancer in Ardabil province, Iran (Pourfarzi et al., 2009; Babaei et al., 2010). The association between $H$. pylori infection and smoking is controversial. In an study into the factors related with $H$. pylori infection in Glasgow, U.K., found that ex-smokers (71\%) and current cigarette smokers $(73 \%)$ have higher occurrence than never-smokers $(59 \%)$, but similar prevalence to each other (Woodward et al., 2000). After adjustment for age, social class, sex, and number of siblings, smokers and ex-smokers were at a higher risk for the infection than subjects who never smoked (Odd ratio (OR): 1.5; 95\% confidence interval (95\% CI): 1.1-1.9 and OR: 1.4; (Woodward et al., 2000). Other reports from the literature showed no association of smoking with $H$. pylori infection (Camargo et al., 2004). Smokers often share cigarettes; therefore, the act of smoking involves inserting orally the tip of a cigarette, which may well have been handled by other people (Tyas and Pederson, 1998). However, smoking is also characteristic of low social status, and the smoking effect could simply be a proxy for other socioeconomic factors such as income and education (Fiedorek et al., 1991).

\section{Alcohol Consumption}

First, self-reporting of alcohol consumption is unreliable as the measurement of the quantity of alcohol consumption is not standardized. Secondly, recall bias in case-control study may affect the result significantly. Lastly, alcohol effect may be so small that the effect could not be shown in past studies. It has been shown ingestion of alcohol is associated with development of distal, but not proximal GC (Tramacere et al., 2012). Recently, 
two prospective large cohort studies reported positive association between alcohol consumption and GC risk. In the European Prospective Investigation into Cancer and Nutrition study, heavy consumption of alcohol (>60 $\mathrm{g} /$ day) was found to be positively associated with the risk of intestinal type non-cardia GC in men with HR (95\%CI) 1.65 (1.06-2.58) (Duell et al., 2011). In a population based cohort study in Shanghai, China, heavy drinkers were found to have significantly increased risk of GC with HR (95\% CI) of 1.46 (1.05-2.04) (Moy et al., 2010).

\section{Dietary Risk Factors for GC}

Epidemiologic studies have been shown an association between diet and GC risk worldwide. Substantial evidence from ecological, case control, and cohort studied have been proved that the diets that are highly linked to GC risk are those rich in salt, pickled, smoked or poorly preserved foods, those with a high quantity of meat, low fruit, and vegetable content (Epplein et al., 2008; Kim et al., 2010; Gonzalez et al., 2012; Ren et al., 2012)

\section{Salt Intake}

The high consumption of salt, has been demonstrated to be linked with an increased GC risk (Tsugane and Sasazuki, 2007). Dietary salt intake varies among populations, in some populations with a high incidence of GC it is reported that average salt consumption is 49 gram per day (You et al., 1988). One study on urinary sodium exertion has been shown an intense correlation between the salt consumption and GC morality rates (Joossens et al., 1996). Experiments have also been shown that $H$. pylori gene expression has changed in response to the level of sodium chloride (Gancz et al., 2008; Loh et al., 2012). The high level of sodium chloride leads to changes in $H$. pylori cells shape from a typical spiral to elongated form and an upregulation of $\operatorname{cag} A$ gene in some strains. Epidemiological studies have also indicated that $H$. pylori infection and a high salt diet could independently and significantly induce atrophic gastritis and intestinal metaplasia (Gancz et al., 2008; Brenner et al., 2009; Wang et al., 2009; D'Elia et al., 2012).

\section{Fruit and Vegetable Consumption}

Meta-analyses of case-control studies have illustrated that a high consumption of fruits and non-starchy vegetables are remarkably against the development of stomach cancer $(\mathrm{OR}=0.62$ and $95 \% \mathrm{CI}=0.46)$, which is an impact that is stronger in Asia than in United States or Europe (Wiseman, 2008). Particularly, flavonoid consumption is significantly correlated with a reduction in GC risk in women (Wiseman, 2008). Vitamin C, probably through its antioxidant effect, has also known as beneficial factor against the development of GC (Jenab et al., 2006). Over the last century, vast number of changes have occurred in methods of keeping and preserving food in developed countries, the availability of refrigeration led to an increased intake of fresh food (Correa, 2013). The gradual decline in the incidence of GC may be because of the changes in diet that have accompanied refrigeration (Cover and Peek, 2013).

\section{Iron Deficiency}

Iron deficiency have been associated with an increased risk for GC and neoplasms that arise elsewhere in the gastrointestinal tract (Ioannou et al., 2002; Pra et al., 2009; van Lee et al., 2011). Colonization by $H$. pylori strains has been correlated with hemorrhagic gastritis and finally loss of iron (Yip et al., 1997). Long-term H.pylori infection can lead to the development of hypochlorydia, reduced ascorbic acid levels, and subsequently reduced absorption of iron (Waring et al., 1996). Case-control studies have shown an inverse association between dietary iron intake and gastric adenocarcinoma, experiments on serum ferritin have also been shown an inverse association with GC which was more sever in cases diagnosed within 15 years of examination $(\mathrm{P}-\mathrm{value}=0.02)$ (Knekt et al., 1994; Harrison et al., 1997). Based on these studies it is demonstrated that the iron deficiency from both blood loss and a low-iron diet is relevant.

\section{Cholesterol Intake}

H. pylori is auxotrophic for cholesterol, and so the dietary quantity of cholesterol could have an effect on colonization of $H$. pylori in the stomach is related to gastric disease. In vitro studies have been shown that $H$. pylori extracts lipid from plasma membranes of epithelial cells for subsequent glycosylation. Extra cholesterol can increase the level of phagocytosis of $H$.pylori by antigenpresenting cells, including macrophages and dendritic cells, and promotes antigen-specific $\mathrm{T}$ cell responses (Wunder et al., 2006). A diet rich in cholesterol results in T-cell-dependent reduction of the H.pylori in the gastric, therefore a cholesterol-rich diet may decrease the risk of subsequent inflammation and injury caused by $H$. pylori (Cover and Peek, 2013).

\section{Other Risk Factors}

It has been indicated that higher concentration of selenium and zinc in drinking water may be as protective factors against gastric carcinogenesis (Nakaji et al., 2001) It has been demonstrated that high exposure to radon, radium or natural uranium in drinking water has been associated with the risk of GC (Auvinen et al., 2005).

The other environmental carcinogens that might be responsible for the incidence of GC is the high level of nitrate in food particularly in agricultural products that needs more research (Derakhshan et al., 2008).

\section{Conclusion}

Several factors including properties of the $H$. pylori, host genetics, and environmental exposure particularly diet may play a remarkable role in gastric carcinogenesis; each has significant role on the level of long-term interactions between $H$. pylori and humans. It has been proved that approximately $50 \%$ of the world's population is infected with $H$.pylori but a small proportion develops GC. There is great interest in recognition of subpopulations at high risk for disease. Our future goals are to gain deeper insight into the pathogenesis of $H$. pylori in relation to environmental factors especially 
dietary factors, not only to find the developed means for preventing and treating GC, but also for understanding the role of chronic inflammation in the development of other malignancies. The use of appropriate diet could reduce levels of $H$. pylori colonization or virulence and prevent or delay development of peptic ulcer or gastric carcinoma, is attractive from a number of perspectives including those of cost, treatment tolerability, and cultural acceptability.

\section{References}

Akopyants NS, Clifton SW, Kersulyte D, et al (1998). Analyses of the cag pathogenicity island of Helicobacter pylori. Mol Microbiol, 28, 37-53.

Amieva MR, Vogelmann R, Covacci A, et al (2003). Disruption of the epithelial apical-junctional complex by Helicobacter pylori cagA. Science, 300, 1430-4.

Auvinen A, Salonen L, Pekkanen J, et al (2005). Radon and other natural radionuclides in drinking water and risk of stomach cancer: a case-cohort study in Finland. Int J Cancer, 114, 109-13.

Babaei M, Pourfarzi F, Yazdanbod A, et al (2010). Gastric cancer in Ardabil, Iran-a review and update on cancer registry data. Asian Pac J Cancer Prev, 11, 595-9.

Blaser MJ, Berg DE (2001). Helicobacter pylori genetic diversity and risk of human disease. J Clin Invest, 107, 767-73.

Boquet P, Ricci V (2012). Intoxication strategy of Helicobacter pylori VacA toxin. Trends Microbiol, 20, 165-74.

Brenner H, Rothenbacher D, Arndt V (2009). Epidemiology of stomach cancer. Methods Mol Biol, 472, 467-77.

Camargo MC, Lazcano-Ponce E, Torres J, et al (2004). Determinants of Helicobacter pylori seroprevalence in Mexican adolescents. Helicobacter, 9, 106-14.

Correa P (1992). Human gastric carcinogenesis: a multistep and multifactorial process--first american cancer society award lecture on cancer epidemiology and prevention. Cancer Res, 52, 6735-40.

Correa P (2013). Gastric cancer: overview. Gastroenterol Clin North Am, 42, 211-7.

Cover TL, Blanke SR (2005). Helicobacter pylori VacA, a paradigm for toxin multifunctionality. Nat Rev Microbiol, 3, 320-32.

Cover TL, Krishna US, Israel DA, et al (2003). Induction of gastric epithelial cell apoptosis by Helicobacter pylori vacuolating cytotoxin. Cancer Res, 63, 951-7.

Cover TL, Peek RM, Jr. (2013). Diet, microbial virulence, and Helicobacter pylori-induced gastric cancer. Gut Microbes, 4, 482-93.

D'Elia L, Rossi G, Ippolito R, et al (2012). Habitual salt intake and risk of gastric cancer: a meta-analysis of prospective studies. Clin Nutr, 31, 489-98.

de Martel C, Ferlay J, Franceschi S, et al (2012). Global burden of cancers attributable to infections in 2008: a review and synthetic analysis. Lancet Oncol, 13, 607-15.

Derakhshan MH, Malekzadeh R, Watabe H, et al (2008). Combination of gastric atrophy, reflux symptoms and histological subtype indicates two distinct aetiologies of gastric cardia cancer. Gut, 57, 298-305.

Duell EJ, Travier N, Lujan-Barroso L, et al (2011). Alcohol consumption and gastric cancer risk in the European Prospective Investigation into Cancer and Nutrition (EPIC) cohort. Am J Clin Nutr, 94, 1266-75.

Epplein M, Nomura AM, Hankin JH, et al (2008). Association of Helicobacter pylori infection and diet on the risk of gastric cancer: a case-control study in Hawaii. Cancer Causes Control, 19, 869-77.
Epplein M, Zheng W, Li H, et al (2014). Diet, Helicobacter pylori strain-specific infection, and gastric cancer risk among Chinese men. Nutr Cancer, 66, 550-7.

Ferlay J, Steliarova-Foucher E, Lortet-Tieulent J, et al (2013). Cancer incidence and mortality patterns in Europe: estimates for 40 countries in 2012. Eur J Cancer, 49, 1374-403.

Ferreira RM, Machado JC, Letley D, et al (2012). A novel method for genotyping the Helicobacter pylori vacA intermediate region directly in gastric biopsy specimens. J Clin Microbiol, 50, 3983-9.

Fiedorek SC, Malaty HM, Evans DL, et al (1991). Factors influencing the epidemiology of Helicobacter pylori infection in children. Pediatrics, 88, 578-82.

Franco AT, Israel DA, Washington MK, et al (2005). Activation of beta-catenin by carcinogenic Helicobacter pylori. Proc Natl Acad Sci U S A, 102, 10646-51.

Gancz H, Jones KR, Merrell DS (2008). Sodium chloride affects Helicobacter pylori growth and gene expression.J Bacteriol, 190, 4100-5.

Gonzalez CA, Figueiredo C, Lic CB, et al (2011). Helicobacter pylori $\operatorname{cag} A$ and vacA genotypes as predictors of progression of gastric preneoplastic lesions: a long-term follow-up in a high-risk area in Spain. Am J Gastroenterol, 106, 867-74.

Gonzalez CA, Lujan-Barroso L, Bueno-de-Mesquita HB, et al (2012). Fruit and vegetable intake and the risk of gastric adenocarcinoma: a reanalysis of the European prospective investigation into cancer and nutrition (EPIC-EURGAST) study after a longer follow-up. Int J Cancer, 131, 2910-9.

Haile RW, John EM, Levine AJ, et al (2012). A review of cancer in U.S. Hispanic populations. Cancer Prev Res (Phila), 5, 150-63.

Harrison LE, Zhang ZF, Karpeh MS, et al (1997). The role of dietary factors in the intestinal and diffuse histologic subtypes of gastric adenocarcinoma: a case-control study in the U.S. Cancer, 80, 1021-8.

Hennig EE, Mernaugh R, Edl J, et al (2004). Heterogeneity among Helicobacter pylori strains in expression of the outer membrane protein BabA. Infect Immun, 72, 3429-35.

Higashi H, Tsutsumi R, Muto S, et al (2002). SHP-2 tyrosine phosphatase as an intracellular target of Helicobacter pylori cagA protein. Science, 295, 683-6.

Honarmand-Jahromy S, Siavoshi F, Malekzadeh R, et al (2015). Reciprocal impact of host factors and Helicobacter pylori genotypes on gastric diseases. World J Gastroenterol, 21, 9317-27.

Ioannou GN, Rockey DC, Bryson CL, et al (2002). Iron deficiency and gastrointestinal malignancy: a populationbased cohort study. Am J Med, 113, 276-80.

Jemal A, Bray F, Center MM, et al (2011). Global cancer statistics. CA Cancer J Clin, 61, 69-90.

Jenab M, Riboli E, Ferrari P, et al (2006). Plasma and dietary vitamin $\mathrm{C}$ levels and risk of gastric cancer in the European Prospective Investigation into Cancer and Nutrition (EPICEURGAST). Carcinogenesis, 27, 2250-7.

Joossens JV, Hill MJ, Elliott P, et al (1996). Dietary salt, nitrate and stomach cancer mortality in 24 countries. European Cancer Prevention (ECP) and the INTERSALT Cooperative Research Group. Int J Epidemiol, 25, 494-504.

Kim HJ, Lim SY, Lee JS, et al (2010). Fresh and pickled vegetable consumption and gastric cancer in Japanese and Korean populations: a meta-analysis of observational studies. Cancer Sci, 101, 508-16.

Knekt P, Reunanen A, Takkunen H, et al (1994). Body iron stores and risk of cancer. Int J Cancer, 56, 379-82.

Ladeiras-Lopes R, Pereira AK, Nogueira A, et al (2008). Smoking and gastric cancer: systematic review and metaanalysis of cohort studies. Cancer Causes Control, 19, 
689-701.

Loh JT, Friedman DB, Piazuelo MB, et al (2012). Analysis of Helicobacter pylori $\operatorname{cag} A$ promoter elements required for salt-induced upregulation of cagA expression. Infect Immun, 80, 3094-106.

Matsuhisa TM, Yamada NY, Kato SK, et al (2003). Helicobacter pylori infection, mucosal atrophy and intestinal metaplasia in Asian populations: a comparative study in age-, genderand endoscopic diagnosis-matched subjects. Helicobacter, 8, 29-35.

Megraud F (2001). Impact of Helicobacter pylori virulence on the outcome of gastroduodenal diseases: lessons from the microbiologist. Dig Dis, 19, 99-103.

Moy KA, Fan Y, Wang R, et al (2010). Alcohol and tobacco use in relation to gastric cancer: a prospective study of men in Shanghai, China. Cancer Epidemiol Biomarkers Prev, 19, 2287-97.

Murata-Kamiya N, Kurashima Y, Teishikata Y, et al (2007). Helicobacter pylori cagA interacts with E-cadherin and deregulates the beta-catenin signal that promotes intestinal transdifferentiation in gastric epithelial cells. Oncogene, 26, 4617-26.

Nakaji S, Fukuda S, Sakamoto J, et al (2001). Relationship between mineral and trace element concentrations in drinking water and gastric cancer mortality in Japan. Nutr Cancer, 40, 99-102.

Ogiwara H, Sugimoto M, Ohno T, et al (2009). Role of deletion located between the intermediate and middle regions of the Helicobacter pylori vacA gene in cases of gastroduodenal diseases. J Clin Microbiol, 47, 3493-500.

Pourfarzi F, Whelan A, Kaldor J, et al (2009). The role of diet and other environmental factors in the causation of gastric cancer in Iran--a population based study. Int J Cancer, $\mathbf{1 2 5}$, 1953-60.

Pra D, Rech Franke SI, Pegas Henriques JA, et al (2009). A possible link between iron deficiency and gastrointestinal carcinogenesis. Nutr Cancer, 61, 415-26.

Ren JS, Kamangar F, Forman D, et al (2012). Pickled food and risk of gastric cancer--a systematic review and metaanalysis of English and Chinese literature. Cancer Epidemiol Biomarkers Prev, 21, 905-15.

Rhead JL, Letley DP, Mohammadi M, et al (2007). A new Helicobacter pylori vacuolating cytotoxin determinant, the intermediate region, is associated with gastric cancer. Gastroenterol, 133, 926-36.

Shaffer CL, Gaddy JA, Loh JT, et al (2011). Helicobacter pylori exploits a unique repertoire of type IV secretion system components for pilus assembly at the bacteria-host cell interface. PLoS Pathog, 7, 1002237.

Shikata K, Doi Y, Yonemoto K, et al (2008). Population-based prospective study of the combined influence of cigarette smoking and Helicobacter pylori infection on gastric cancer incidence: the Hisayama Study. Am J Epidemiol, 168, 1409-15.

Soerjomataram I, Lortet-Tieulent J, Parkin DM, et al (2012). Global burden of cancer in 2008: a systematic analysis of disability-adjusted life-years in 12 world regions. Lancet, 380, $1840-50$.

Sonnenberg A (2010). Differences in the birth-cohort patterns of gastric cancer and peptic ulcer. Gut, 59, 736-43.

Suzuki R, Shiota S, Yamaoka Y (2012). Molecular epidemiology, population genetics, and pathogenic role of Helicobacter pylori. Infect Genet Evol, 12, 203-13.

Torres VJ, VanCompernolle SE, Sundrud MS, et al (2007). Helicobacter pylori vacuolating cytotoxin inhibits activationinduced proliferation of human T and B lymphocyte subsets. J Immunol, 179, 5433-40.
Tramacere I, Negri E, Pelucchi C, et al (2012). A meta-analysis on alcohol drinking and gastric cancer risk. Ann Oncol, 23, 28-36.

Tsugane S, Sasazuki S (2007). Diet and the risk of gastric cancer: review of epidemiological evidence. Gastric Cancer, 10, 75-83.

Tyas SL, Pederson LL (1998). Psychosocial factors related to adolescent smoking: a critical review of the literature. $T o b$ Control, 7, 409-20.

van Lee L, Heyworth J, McNaughton S, et al (2011). Selected dietary micronutrients and the risk of right- and left-sided colorectal cancers: a case-control study in Western Australia. Ann Epidemiol, 21, 170-7.

Wang XQ, Terry PD, Yan H (2009). Review of salt consumption and stomach cancer risk: epidemiological and biological evidence. World J Gastroenterol, 15, 2204-13.

Waring AJ, Drake IM, Schorah CJ, et al (1996). Ascorbic acid and total vitamin $\mathrm{C}$ concentrations in plasma, gastric juice, and gastrointestinal mucosa: effects of gastritis and oral supplementation. Gut, 38, 171-6.

Winter JA, Letley DP, Cook KW, et al (2014). A role for the vacuolating cytotoxin, $\mathrm{VacA}$, in colonization and Helicobacter pylori-induced metaplasia in the stomach. $J$ Infect Dis, 210, 954-63.

Wiseman M (2008). The second World Cancer Research Fund/ American Institute for Cancer Research expert report. Food, nutrition, physical activity, and the prevention of cancer: a global perspective. Proc Nutr Soc, 67, 253-6.

Woodward M, Morrison C, McColl K (2000). An investigation into factors associated with Helicobacter pylori infection. $J$ Clin Epidemiol, 53, 175-81.

Wu X, Chen VW, Andrews PA, et al (2007). Incidence of esophageal and gastric cancers among Hispanics, nonHispanic whites and non-Hispanic blacks in the United States: subsite and histology differences. Cancer Causes Control, 18, 585-93.

Wunder C, Churin Y, Winau F, et al (2006). Cholesterol glucosylation promotes immune evasion by Helicobacter pylori. Nat Med, 12, 1030-8.

Yamaguchi N, Kakizoe T (2001). Synergistic interaction between Helicobacter pylori gastritis and diet in gastric cancer. Lancet Oncol, 2, 88-94.

Yip R, Limburg PJ, Ahlquist DA, et al (1997). Pervasive occult gastrointestinal bleeding in an Alaska native population with prevalent iron deficiency. Role of Helicobacter pylori gastritis. JAMA, 277, 1135-9.

You WC, Blot WJ, Chang YS, et al (1988). Diet and high risk of stomach cancer in Shandong, China. Cancer Res, 48 , 3518-23. 